\title{
ANESTESIA PARA COELHOS SUBMETIDOS A CIRURGIAS DE EXPERIMENTAÇÃO: RELATO DE SÉRIE DE OITO ANESTESIAS
}

\section{ARTIGO ORIGINAL}

BEDIN, Rafael Antonio Caldart ${ }^{1}$

SCHULTZ, Maisa ${ }^{2}$

BEDIN, Antonio ${ }^{3}$

BEDIN, Rafael Antonio Caldart. SCHULTZ, Maisa. BEDIN, Antonio. Anestesia para coelhos submetidos a cirurgias de experimentação: Relato de série de oito anestesias. Revista Científica Multidisciplinar Núcleo do Conhecimento. Ano 05, Ed. 06, Vol. 03, pp. 151-158. Junho de 2020. ISSN: 2448-0959, Link de acesso: https://www.nucleodoconhecimento.com.br/saude/anestesia-para-coelhos

\section{RESUMO}

A anestesia para animais de laboratório é motivo de preocupação biomédica e um dos dilemas mais presentes no debate bioético atual. A utilização de agentes anestésicos em cirurgia experimental tem por objetivo a analgesia e a contenção do animal, de forma a atingir um grau razoável de relaxamento muscular e de produzir analgesia suficiente. Esta prática requer utilização de protocolos para a administração de doses seguras e eficientes. Foram oito coelhos da raça da nova Zelândia submetidos a laparotomias demonstrativas da disciplina de técnica operatória do curso médico local. Para a medicação pré-anestésica foi utilizado acepromazina $1 \mathrm{mg} \cdot \mathrm{kg}^{-1}$ associada a cetamina $15 \mathrm{mg} \cdot \mathrm{kg}^{-1}$ por via subcutânea. A manutenção da anestesia foi com isoflurano e oxigênio sob máscara laríngea em sistema de anestesia de Mapleson $D$

\footnotetext{
${ }^{1}$ Graduando em medicina.

2 Graduanda de medicina.

${ }^{3}$ Médico Anestesiologista. Mestre em Saúde. Doutor em Anestesiologia.
} 
e sob respiração espontânea. A hidratação foi realizada com soro fisiológico $10 \mathrm{ml} . \mathrm{kg}$ 1 a cada hora. Utilizou-se colchão térmico. Para a monitorização foi utilizado estetoscópio precordial, oximetria de pulso e parâmetros clínicos. Para a eutanásia utilizou-se cetamina $10 \mathrm{mg} \cdot \mathrm{kg}^{-1}$ associada a cloreto de potássio $19,1 \% 1 \mathrm{ml} \cdot \mathrm{kg}^{-1}$ por via venosa. O peso médio dos coelhos foi $2721,25 \pm 275,01$ gramas e a duração do procedimento anestésico foi $120 \pm 87$ minutos. Discussão. Nas anestesias de longa duração, como as laparotomias, recomenda-se e a utilização de medicação préanestésica e posteriormente a indução anestésica feita pela combinação de agentes. Entretanto, o manejo anestésico requer monitoração para evitar que doses insuficientes ou exageradas ocorram.

Palavras Chaves: Coelhos, isoflurano, anestesia geral.

\section{INTRODUÇÃO}

A anestesia para animais de laboratório é motivo de debate ético e tem sido um dos tópicos mais conflitantes neste campo do conhecimento (BEDIN et.al., 2013). O uso de anestésicos em cirurgia experimental tem por objetivo a contenção do animal, de forma a atingir um grau razoável de relaxamento muscular e de produzir analgesia suficiente. Esta prática requer utilização de protocolos para a administração de doses seguras e eficientes (BEDIN et.al., 2013).

\section{REVISÃO BIBLIOGRÁFICA}

Coelhos usualmente apresentam estresse pelo manuseio pré-operatório e durante a medicação pré-anestésica e durante a indução com agentes anestésicos venosos ou voláteis. Aqui pode somar o estresse com o a manipulação do animal para a administração da anestesia podendo resultar em parada respiratória e cardíaca. A ocorrência de infecção respiratória por Pasteurella multocida pode levar a intercorrências respiratórias graves durante a anestesia. No exame pré-operatório destes animais devemos prestar muita atenção à presença de sintomas respiratórios (coriza e ruídos adventícios à ausculta), o que podem ser fortes indicativos de infecção do trato respiratório (BEDIN et.al.,2013). 
As anestesias em coelhos podem variar desde uma simples sedação até planos profundos de anestesia os quais permitem a realização de procedimentos cirúrgicos de menor e maior porte. A utilização de anestésicos voláteis halogenados em coelhos é frequentemente utilizada para procedimentos de longa duração principalmente quando é almejado manter-se a homeostasia dos animais o mais equilibrada possível (BEDIN et.al., 2013).

Após a administração da medicação pré-anestésica, aguarda-se 15 minutos para que seja adaptada a máscara laríngea, conectando-a ao aparelho de anestesia. Pode-se utilizar $\mathrm{O}_{2}$ de 50 a $100 \%$ e isoflurano de 1 a $5 \%$ (BEDIN et.al.,2013; RAILLARD et.al.,2019; TUNCALI et.al., 2018). O procedimento de intubação traqueal apresenta grande dificuldade técnica quando os animais são coelhos (BEDIN et.al., 2013). A visualização da glote com laringoscópio é praticamente impossível nestes animais (BEDIN et.al.,2013). A técnica às cegas, orientada pela a respiração costuma ser o modo mais frequente para a intubação em coelhos. Pela dificuldade de intubação traqueal a traqueostomia ou máscaras laríngeas são utilizadas por muitos que atuam nesta área (THOMPSON et.al., 2017). Os procedimentos anestésicos em coelhos podem ser mantidos sob máscara facial ou máscara laríngea com oxigênio e agente anestésico halogenado em respiração espontânea (BEDIN et.al., 2013).

Nos procedimentos em que se tem a necessidade de ventilação pulmonar esta pode ser manual, com a utilização de um sistema de Mapleson D, ou ventilação controlada mecânica com aparelho que disponha de filtro circular (BEDIN et.al., 2013). A monitorização é principalmente baseada na clínica pela observação de dados vitais tais como frequência cardíaca, frequência respiratória, coloração de mucosas e presença de reflexos oculopalpebrais. Rotineiramente são utilizados para esta monitorização estetoscópio precordial, eletrocardioscópio e oximetria de pulso. Os demais monitores devem ser utilizados conforme as necessidades impostas pelo desenho do estudo, sendo que podem ser úteis capnógrafos, pressão arterial invasiva e não invasiva.

O período pós-operatório faz parte do protocolo anestésico, sendo fundamentais os cuidados ministrados ao animal neste momento. Complicações como a depressão 
respiratória, que pode ocorrer durante 0 ato anestésico, se tornam fatais neste período. Após o término do procedimento anestésico-cirúrgico os animais devem ser encaminhados para a recuperação anestésica. Este local deve permanecer silencioso, com baixa luminosidade, e para se evitar o estresse dos animais, deve se ter o mínimo de manipulação. Se a eutanásia estiver prevista no protocolo do estudo as técnicas para este mister devem proporcionar inconsciência seguida por cessação dos batimentos cardíacos e respiratórios e término definitivo das funções cerebrais. O ideal seria que a técnica minimizasse a ansiedade experimentada pelo animal antes da perda da consciência.

Para coelhos as técnicas mais utilizadas para eutanásia são: $\mathrm{CO}_{2}$ inalado, agentes inalatórios, barbitúricos venosos e cloreto de potássio por via venosa, este somente sendo utilizado em animais sob sedação profunda pois a injeção venosa é dolorosa (BEDIN et.al.,2013).

Com base nestes dados da literatura tem sido adotado como procedimento anestésico utilizado como rotineiramente na disciplina de Técnica Operatória e Anestesiologia do Curso de Medicina da Universidade da Região de Joinville (UNIVILLE) para anestesia em coelhos (BEDIN et.al., 2013):

1. Após a identificação realiza-se a pesagem: esta identificação e o registro dos animais são partes integrantes do pré-operatório. Após a pesagem, este animal deve ser identificado com seu número e o peso correspondente.

2. Para a medicação pré-anestésica utiliza-se acepromazina $1 \mathrm{mg} \cdot \mathrm{kg}^{-1}$ e cetamina $15 \mathrm{mg} \cdot \mathrm{kg}^{-1}$ subcutâneo em torno de quinze a vinte minutos antes do início da tricotomia.

3. A tricotomia é realizada na região anterior do pescoço, no abdômen e na margem da orelha.

4. É realizada a imobilização sobre a mesa operatória sempre.

5. A cateterização venosa é realizada na veia marginal da orelha, com cateter 24 G. Posteriormente é realizada a instalação venosa de soro fisiológico 0,9\% 250 $\mathrm{ml}$. 
6. Para a anestesia utiliza-se cetamina 5 a $10 \mathrm{mg} . \mathrm{kg}-1$ venosa em doses sequenciais, se houver necessidade. Para a ventilação utiliza-se máscara laríngea número 1. Em certas situações (cirurgias torácicas) se procede a intubação traqueal com cânula número 2 ou 3 ou traqueostomia.

7. A monitorização é realizada com estetoscópio precordial (ou se possível, esofágico), oximetria de pulso (quando disponível) e eletrocardioscópia (quando disponível).

8. Para a anestesia inalatória utilizada para a manutenção consta de isoflurano de $1 \%$ a $3 \%$ e oxigênio dois a três litros por minuto sob máscara em sistema Mapleson D.

9. Para a elaboração da ficha de anestesia anotam-se os sinais vitais a cada 5 a 10 minutos.

10. Durante o período pós-anestésico anotam-se os dados do início da recuperação até o restabelecimento da consciência e os padrões fisiológicos estarem dentro do normal.

11. Para o controle de dor pós-operatória utiliza-se paracetamol por via oral entre 10 a 15 mg.kg-1, três vezes ao dia tendo aqui como alternativa a dipirona.

12. Se o protocolo do estudo prevê a eutanásia esta poderá ser realizada em câmara de inalação de $\mathrm{CO}_{2}$ com $10 \mathrm{I}$. $\mathrm{min}^{-1}$ por 10 minutos. A segunda escolha

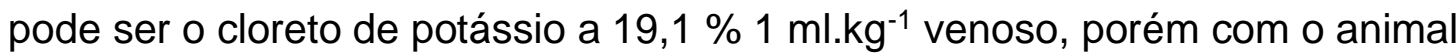
sedado com cetamina 1 a $10 \mathrm{mg} \mathrm{mg.kg-1}$ venosa ou subcutânea quinze a vinte minutos antes do cloreto de potássio (BEDIN et.al., 2013).

\section{RELATO DOS CASOS}

As anestesias que fazem parte desta série foram autorizadas pelo Comitê de Ética em Pesquisa no Uso de Animais da Universidade da Região de Joinville (CEUA) número 0103/2018.

Foram oito coelhos da raça da nova Zelândia submetidos a laparotomias demonstrativas da disciplina de técnica operatória do curso médico local (tabela 1). 
Tabela 1. Dados demográficos.

\begin{tabular}{|l|l|l|}
\hline $\begin{array}{l}\text { Número } \\
\text { de } \\
\text { animais }\end{array}$ & $\begin{array}{l}\text { Peso } \\
\text { gramas }\end{array}$ & $\begin{array}{l}\text { Duração em } \\
\text { minutos }\end{array}$ \\
\hline $\mathbf{8}$ & $2721,25 \pm 275,01$ & $120,87 \pm 19,96$ \\
\hline
\end{tabular}

Fonte: autores.

Para a medicação pré-anestésica foi utilizado acepromazina $1 \mathrm{mg} \cdot \mathrm{kg}^{-1}$ associada a cetamina $15 \mathrm{mg} \mathrm{kg}^{-1}$ por via subcutânea (tabela 2).

Tabela 2. Medicação pré-anestésica e intraoperatória.

\begin{tabular}{|c|c|c|c|c|}
\hline $\begin{array}{l}\text { Número } \\
\text { de } \\
\text { animais }\end{array}$ & $\begin{array}{l}\text { Acepromazina } \\
\text { em mg pré- } \\
\text { anestésica } \\
\text { (média } \pm d e s v i o \\
\text { padrão) }\end{array}$ & $\begin{array}{l}\text { Cetamina em } \\
\text { mg pré- } \\
\text { anestésica } \\
\text { (média } \pm d e s v i o \\
\text { padrão) }\end{array}$ & $\begin{array}{l}\text { Cetamina em } \\
\text { mg venosa } \\
\text { intraoperatória } \\
\text { (média } \pm \text { desvio } \\
\text { padrão) }\end{array}$ & $\begin{array}{l}\text { Isoflurano em } \\
\text { ml } \\
\text { (média } \pm \text { desvio } \\
\text { padrão) }\end{array}$ \\
\hline 8 & $2,68 \pm 0,29$ & $38,75 \pm 5,82$ & $37,5 \pm 20,35$ & $41,37 \pm 8,36$ \\
\hline
\end{tabular}

Fonte: autores.

Para a manutenção da anestesia foi utilizado isoflurano e oxigênio em vaporizador não calibrado após a passagem de máscara laríngea número 1 e sistema de anestesia inalatória Mapleson D sob respiração espontânea sempre. A hidratação foi com soro fisiológico $10 \mathrm{ml}^{.} \mathrm{kg}^{-1}$ (tabela 2). Utilizou-se colchão térmico. Para a monitorização foi utilizado estetoscópio precordial, oximetria de pulso e parâmetros clínicos (movimentos involuntários, reflexo oculopalpebral). Para a eutanásia utilizou-se cetamina $10 \mathrm{mg} \cdot \mathrm{kg}^{-1}$ venosa seguida 5 a 15 minutos após por cloreto de potássio $19,1 \% 1 \mathrm{ml}^{\mathrm{kg}}{ }^{-1}$, também por via venosa (tabela 3 ). 
Tabela 3. Medicação para eutanásia.

\begin{tabular}{|l|l|l|}
\hline $\begin{array}{l}\text { Número de } \\
\text { animais }\end{array}$ & $\begin{array}{l}\text { Cetamina em mg } \\
\text { (média } \pm \text { desvio } \\
\text { padrão) }\end{array}$ & $\begin{array}{l}\text { Cloreto de potássio } \\
\text { em ml }\end{array}$ \\
\hline $\mathbf{8}$ & $\begin{array}{l}\text { (média } \pm \text { desvio } \\
\text { padrão) }\end{array}$ \\
\hline & $85,12 \pm$ & $3,67 \pm 1,12$ \\
\hline
\end{tabular}

\section{DISCUSSÃO}

O isoflurano é utilizado com frequência como agente único ou associado a opioides para procedimentos anestésicos em coelhos (BAILEY et.al., 2017; TEARNEY et.al.,2015). A administração de fentanil em coelhos anestesiados com isoflurano resultou em melhor pressão arterial média e débito cardíaco, em comparação com o isoflurano isolado (BAILEY e et.al., 2017; TEARNEY et.al., 2015). A acepromazina (tranquilizante maior) e a cetamina (anestésico dissociativo) são medicações utilizadas com frequência como medicação pré-anestésica e anestésicas para coelhos $^{1,8,9}$. Tanto a acepromazina quanto a cetamina reduzem o consumo de isoflurano como anestésico principal em coelhos (BEDIN et.al., 2013; BOTMAN et.al., 2019; ECKLEY et.al., 2020).

\section{CONCLUSÃO}

Nas anestesias de longa duração, como as laparotomias, recomenda-se e a utilização de medicação pré-anestésica e posteriormente a indução anestésica feita pela combinação de agentes (ECKLEY et.al., 2020). Entretanto, o manejo anestésico requer monitoração para evitar que doses insuficientes ou exageradas ocorram. Para evitar que variações aconteçam, recomenda-se a monitorização dos sinais vitais desde o início do manejo dos animais submetidos anestesia inalatória e todo o período durante o qual a anestesia é mantida até a eutanásia (BEDIN et.al., 2013). 


\section{REFERÊNCIAS}

ATALAN, Güneri e colab. Comparison of systemic effects of midazolam, ketamine, and isoflurane anaesthesia in rabbits. Journal of Veterinary Research (Poland), v. 63, n. 2, p. 275-283, 2019.

BAILEY, Ryan S. e BARTER, Linda S. e PYPENDOP, Bruno H. Pharmacokinetics of dexmedetomidine in isoflurane-anesthetized New Zealand White rabbits. Veterinary Anaesthesia and Analgesia, v. 44, n. 4, p. 876-882, 1 Jul 2017.

BEDIN, Antonio e JUNIOR, Harry e KRELING, Patricia. Anestesia para cirurgia experimental em coelhos. v. 42, n. 2, p. 33-37, 2013.

BOTMAN, Julie e colab. Postanaesthetic effects of ketamine-midazolam and ketamine-medetomidine on gastrointestinal transit time in rabbits anaesthetised with isoflurane. Veterinary Record, 2019.

ECKLEY, Samantha $S$ e colab. Acepromazine and Chlorpromazine as Pharmaceutical-grade Alternatives to Chlorprothixene for Pupillary Light Reflex Imaging in Mice. Journal of the American Association for Laboratory Animal Science : JAALAS, $\quad 8 \quad$ Jan 2020.2 Disponível em: <http://www.ncbi.nlm.nih.gov/pubmed/31915106>. Acesso em: 10 fev 2020.

RAILLARD, Mathieu e colab. Anaesthetic and perioperative management of 14 male new zealand white rabbits for calvarial bone surgery. Animals, v. 9, n. 11, 1 Nov 2019.

TEARNEY, Caitlin C. e BARTER, Linda S. e PYPENDOP, Bruno H. Cardiovascular effects of equipotent doses of isoflurane alone and isoflurane plus fentanyl in New Zealand white rabbits (Oryctolagus cuniculus). American Journal of Veterinary Research, v. 76, n. 7, p. 591-598, 6 Jul 2015. 
THOMPSON, Krista L. e MEIER, Thomas R. e SCHOLZ, Jodi A. Endotracheal intubation of rabbits using a polypropylene guide catheter. Journal of Visualized Experiments, v. 2017, n. 129, 13 Nov 2017.

TUNCALI, Bahattin e colab. Retrospective Evaluation of Patients who Underwent Laparoscopic Bariatric Surgery. Turkish Journal of Anesthesia and Reanimation, v. 46, n. 4, p. 297-304, 16 Ago 2018. Disponível em: <http://www.ncbi.nlm.nih.gov/pubmed/30140537>. Acesso em: 29 set 2019.

Enviado: Abril, 2020.

Aprovado: Junho, 2020. 